\title{
Critical Organisational Success Factors Used In the Evaluation of Training \& Development
}

\author{
Theophilus Tebetso Tshukudu \\ University of Botswana \\ Department of political and Administrative Studies \\ Private Bag UB00705, Gaborone, Botswana \\ Tel: +2673555018Ｅmail: theophilus.tshukudu@mopipi.ub.bw \\ Fax: +2673170706
}

Accepted: August 04, 2014

Doi:10.5296/ jpag.v4i3.6502 URL: http://dx.doi.org/10.5296/ jpag.v4i3.6502

\begin{abstract}
Evaluation of training and development does not take place in a vacuum, but is influenced by various critical organizational success factors. These factors include creating a culture, developing leadership, performance management and creating a learning organization. Various organizational factors are critical to the effective evaluation of training and development initiatives. Evaluation of training and development cannot be separated from organizational culture as culture directs the behavior of employees. As a result, careful attention should be given to establishing a culture that is supportive for the attainment of training and development objectives. The main aim of this article is to highlight the importance of critical organizational success factor for effective evaluation of training and development in the Botswana public service sector.
\end{abstract}

Keywords: Training and Development, success factors, organizational development 


\section{Introduction}

Some of the organisational characteristics that distinguish an effective and efficient organisation from the rest include: establishing a training culture in the organisation, developing leadership that encourages learning in the organisation and lastly, an organisation which manages its employees' performance and appraises them accordingly. Evaluation is an important and integral part of successful training and development. Evaluation can be facilitated through the use of effective strategies, techniques, appropriate approaches, and through the implementation of a performance-management system as has been suggested earlier in the chapter. Also, the fundamentals of evaluation need to be understood in order to communicate the importance of evaluation to trainers and training managers alike. Evaluation of training and development assists managers realise change that occurs due to training. Therefore one of the reasons for evaluating training is to determine effectiveness at individual, team and organisational levels. Performance management is based on a participative decision-making process where individual employees are able to explain their training needs whilst allowing managers to incorporate individual needs into departmental training priorities and thus aligning individual development with departmental effectiveness and efficiency. The whole principle of the evaluation of training and development initiatives is important to the implementation of and management of the learning organisation.

\section{Methodology}

The objective of this section is to describe the research methodology that was used during this study. The section focuses on professional research and design, the population, questionnaire, pilot study, survey and survey response rate. The bibliographical information gathered during the survey is also presented here and discussed. The empirical study was conducted by means of a survey, which allowed for the collection of a large amount of information. A survey gives the researcher more control over the research process, but he/she should then spend adequate time on developing and piloting the questionnaire (De Vos, et al, 2002 , p.94). In this section, the population, the questionnaire, the pilot study, the survey and the research response rate are discussed in detail.

\section{Discussion}

The following will be cover under this section: creating a training culture, develop organisational leadership, develop a learning organization and develop an effective performance management system

\subsection{Creating a training culture}

The training culture indicates to employees what behaviours are acceptable and what types of behaviour are not. As a result, establishing a culture that is supportive to the attainment of excellence in an organisation ensures improved performance. Important questions are therefore, what type of culture is most conducive to effective training and development and how such a culture can be established in the organisation. Johnston and McClelland (1994, p.30) note that the challenge now is to develop a market-driven training culture without losing reliability, and giving meticulous attention to detail, underpinned by sound ethical 
principles, which remain essential to continued and sustained success. There is a common agreement that training and development must be driven by the strategy of the organisation. Due to this scenario, trainers are now expected to define where the emphasis will be on organisational needs through individuals so as to arrive at an organisation which strives for long-term learning, rather than short-term training. These learning demands are continuous and demand meaningful interaction between people and their work environment. An environment which is both supportive and stimulating will lead to considerable learning, and, through this, to individual and organisational growth (Johnston \& McClelland 1994, p.30).

Training and development cannot be separated from the organisational culture as culture directs the behaviour of employees, creates greater commitment to organisational goals and objectives and serves as a yardstick to employees when they have to make decisions and solve problems (Kreitner \& Kinicki 2001, p.75). Hall \& Meh (2004, p.1) suggest that culture is the key to organisational excellence and the creation and management of a performance culture. From the above, it can be concluded that organisational culture is the deep structure of the organisation which consists of the collective values, beliefs and assumptions of organisational members. Therefore, the management of training and development will be more effective in an organisation where training is embedded in the organisational culture. Kreitner and Kinicki (2001, p.75) identify three types of cultures, namely constructive, passive-defensive, and aggressive cultures. A constructive culture is one in which employees are encouraged to interact with others and to work on tasks and projects in a manner that will satisfy their needs for growth and development. This kind of culture is appropriate in a learning environment because it encourages interaction and effective communication between the trainer and the trainees. A constructive culture is more conducive to performance than an aggressive- defensive or passive-defensive culture because in the constructive culture, the organisation values help members to set and accomplish their goals (Kreitner \& Kinicki 2001, p.77). Wright (1994, p.117) provides the following characteristics for an ideal training culture:

- A unifying philosophy and spirit emanating from the top;

- The conscious cultivation of an internal guidance system by inculcating basic values and beliefs;

- Intensive communication;

- Encouragement of internal competition;

- Allowance for mistakes;

- The use of heroes or role models, rites and rituals;

- Work will be meaningful through a general emphasis or orientation on caring and on people rather than the mechanistic side of management.

- Stimulated to achieve superior results;

- Inspired to communicate progress and results; and 
- Willingness to accept responsibility for results.

Robbins (2003, p.528) states that culture influences employees' behaviour. Culture reduces formalisation and creates a common understanding on how employees' efforts are recognised and rewarded. According to Robbins (2003, p.528), a person who receives a job offer, is appraised as a high performer and subsequently gets promoted, is strongly influenced by a positive individual-organisation fit. It means that the applicant's or employee's attitude and behaviour are compatible with the organsitional culture. Culture enhances organisation commitment and increases the consistency of employees' behavior. Culture is valuable because it reduces ambiguity. It tells employees how things are done and what is important. Alu (2004, p.117) states that to establish a culture that supports training, organisations need to give careful attention to their vision and the values they endorse. He further states that successful organisations have strong values and strong guiding visions that communicate appropriate behavior. These values are shared across the organisation and they reflect in the everyday actions of employees, individually and collectively. Organisational culture and values are sources of competitive advantage for the organisation. Culture and values provide a link between the way people are managed and the overall performance of the organisation. From the above discussion, it is clear that a training culture promotes development and growth in the organisation. The next section presents a discussion on the importance of effective leadership in a training environment.

\subsection{Developing organisational leadership}

Friedman (2000, p.181) lists and describes the various characteristics of a training leader and these include:

- Managers are pragmatic visionaries seeing their work in the larger context of the training system as a whole;

- Centrality of values reinforcing the core set of training department values;

- Effective training managers are master strategists and tacticians being able to ascertain how external forces will shape the organisation and as a consequence also being able to articulate a realistic path for the future;

- The essence of organisational training and development is the skillful devolution of power developing the leadership capabilities of subordinates;

- Effective training managers are stewards of learning and will continuously encourage others to learn;

- Training managers are learners themselves despite their capability to direct and strategize; and

- Effective training managers realize that there is no single path for organisational training and would depend on the culture and processes in an organisation.

Leadership in a training environment also contributes to the establishment of an effective learning culture in the organisation (Dobson 2001, p.11). Leaders' influence employees 
through their position of authority and employees become acute observers of how leaders act and frequently emulate their leaders, in words and deeds. Establishing a training culture needs leadership commitment and support for the process through goal setting. Purcell (2004, p.56) emphasises that the behaviour of leaders, who are responsible for both training and performance management, contributes to the establishment of a high performance culture in the organisation.

Daft and Morco (1998, p.420) state that leadership plays an important role in the development and implementation of training and development in the organisation. These authors define leadership as the ability to influence people toward the attainment of goals. A leader is someone who sets direction in an effort to influence people to follow that direction. How leaders influence and set direction depends on the organisational culture. According to McGill (2004, p.136), one study of 167 firms in 13 industries over a 20-year period found that the administration factor (i.e. a combination of leadership and managership) had a limited effect on sales and profits. Re-analysis of the same data found that leadership accounted for more change in performance than other variables studied. McGill (2004, p.124) states that a leader can make a difference by influencing training and subsequently performance, goal attainment, individual growth and development. In the training and development process, the manager draws on his/her personal competencies to influence employees and social competencies to establish a constructive relationship and cognitive competencies to influence the training process.

Effective managers do not give orders and discipline staff. They draw the best from their people through encouragement, support and personal charisma for individual employees to develop (Price 2004, p.18). Blake and Mouton perceive an effective manager as one that has concern for both employee and task and can integrate personal needs and organisational needs. Situational leadership theory, such as that of Hersey and Blanchard, postulates that an effective leader is one who has the ability to organise and spell out the task to the group and maintain a constructive interpersonal relationship with group members (Werner 2003, p.193). From the above discussion, it may be concluded that an effective training manager who is able to lead subordinates into a learning environment, should be aware of his or her own training and development priorities. An effective training manager is able to guide, direct, influence, plan, and implement training and development priorities that would not only address departmental needs but will also be able to attract and retain individual commitment to departmental learning.

\subsection{Develop a performance management system}

There is often confusion about the role of performance management and performance appraisal. It is therefore necessary to understand the difference between the two. In order to clear the confusion about the two concepts, brief definitions of performance management and performance appraisal will be provided. Performance management is an overall strategy to improve performance in an organisation. According to Bacal $(1999$, p.3) and Viedge, Schultz, Bagraim, Portgieter and Werner (2003, p.78), performance appraisal is a sub-component of an overall performance management system. The isolation of performance appraisal from 
other performance management processes will render the entire performance management system inadequate and incomplete. The main difference between performance management and performance appraisal is that performance management is a continuous process while performance appraisal is performed once or twice a year (DPSM 2001, p.12). Training and development cannot improve both employee and organisational performance if there is no performance management system in place. There is a need for organisations to continuously manage and appraise employee performance in order to have effective training and develop programmes addressing issues of poor performance. Both performance management and performance appraisal determine the type and the quality of the training programme to be delivered.

The main objective of this research is to formulate strategies that can be used by the Botswana public service to evaluate the effectiveness of training and development initiatives. In chapter two, the Botswana performance management system was discussed and this section provides guidelines for an effective performance management system and performance appraisal that effectively informs training managers on the type and the quality of training required for the organisation. In order to clarify the function and the role of performance management, the definition of performance management, its purpose and the application at individual, team and organisation level, will be discussed in this section. The discussion will also include how both performance management and performance appraisal influence training and development decisions. Performance management is an ongoing communication process between an employee and his/her immediate supervisor. It involves establishing clear expectations and an understanding of the essential job functions the employee is expected to fulfill, Bacal (1999, p.5) suggests that specific aspects of the employee's job, which should be discussed with him/her, include the following:

- How the employee contributes to the goals of the organisation;

- What performing a job well means in concrete terms;

- How the employee and supervisor will work together to sustain, improve or build on the current performance level of the employee;

- How job performance will be measured; and

- Which barriers prevent performance and how to remove them?

According to Joubert and Noah (2000, p.18), performance management entails formally guiding, directing, measuring, evaluating and rewarding employee effort, competence and talent to achieve organisational strategic objectives. It is therefore evident, that performance management is a combined effort between the supervisor and employee to achieve organisational goals. Performance management is aimed at obtaining better results from individuals, teams and the organisation by understanding and managing performance within an agreed framework of planned goals, standards and competencies (Armstrong 2000, p.45). 
Firstly, performance management is concerned with individual, team and oganisational effectiveness. Secondly, performance management is concerned with continuous employee development. Thirdly, performance management is concerned with satisfying the needs and expectations of all organisation stakeholders which include owners, management, employees, customers, suppliers and the general public. During performance management, the needs of individuals, teams and the organisation should be considered and respected. Finally, performance management is concerned with communication, involvement and participation. It is aimed at creating a climate in which a continuous dialogue between manager and team members takes place to define expectations and share information of the organisation's, mission, values and objectives (Organisational Performance 2000, p.2). In order to understand the scope of performance management in an organisation, three levels of performance management are identified, namely performance management at individual, team and organisational level.

\subsubsection{Performance management at individual level}

The development phase at individual level is concerned with employee skills development and comprehensive performance feedback, which results in the necessary performance adjustments. According to Ivancevich et al (1997, p.7), individual performance is the foundation of organisational performance and the understanding of individual behaviour is therefore critical for the effective management of performance. Viedge et al (2003, p.82) state that a discussion of performance and the understanding of behaviours form the basis of performance improvement. During the discussion, the manager is able to identify the training needs of the individual. The next step is the review, analysis and evaluation of the employee's performance. Management should also establish a reward system that enhances the attainment of individual, team and organisational goals. Once the employee has attained the desired goals, performance goals and responsibilities are redefined. Teams play a crucial role in the modern business and therefore, it is important for the organisation to maximise the capability of teams in achieving their strategic goals. Team performance like individual performance is critical for not only organisational effectiveness, but also for competitiveness. The next section will present a discussion on the management of team performance.

\subsubsection{Performance management at team level}

Performance management actions at team level do not vary from performance management at individual level, except that they are aimed at the collective efforts of team members. For any organisation to perform effectively at team level, interdependent individuals and groups must establish working relationships across organisational boundaries, between individuals, and between groups. The management of individual performance can be used to foster this interdependence. Top management must be committed to the team and the management of its performance. Through their time, attention, and other behaviour, leaders must continually express and reinforce the notion that team work is the only way to achieve planned performance goals. Gibson, Ivancevich and Donelley (1997, p.215) observe that, just like individuals, teams need nurturing and support. It is not enough to develop a mission, goals, and performance strategies for a team without continuously managing its performance. 
Managers must, through team building and communication, co-ordinate and adjust the performance activities of teams to maximise effectiveness. Team performance must continually be reviewed, analysed and evaluated. Organisations also need to establish a reward system for teams. Team rewards must be commensurate with the value of organisational performance and team contribution. Performance expectations for teams are continuously redefined through the development of suitable strategies. It can be concluded that the role of teams in improving organisational performance is equally important as individual performance and therefore it is important to manage team performance to improve the overall organisational performance.

\subsubsection{Performance management at organisational level}

An organisation consists made of individuals and teams whose performance has to be managed continuously. Performance may also be managed at organisational level. This section will cover performance standards and measures, and characteristics of an effective performance management system. Performance management at organisational level begins with the development of a strategic business plan and organisational design which enhances performance management. Performance management at this level also entails a review of organisational performance against the strategic business, training and development plan and financial goals. It can therefore be concluded, that performance management must be based on the strategic plans of the organisation. Individual and team objectives are deduced from the organisational strategic objectives and the strategic human resources development plan of the organisation. From the above discussion, it is evident that the development of a performance management system begins with establishing the advantages of the current management system and re-engineering it according to the strategic needs and objectives of the organisation. The next section focuses on the performance standards and measures.

\subsubsection{Performance standards and measures}

An important aspect in the development of a performance management system is the development of performance standards and measures. The first step is to determine the employee key performance areas, also called critical performance areas. Performance standards and measures are developed for the key performance areas and must subsequently be rectified by training and development. Critical performance areas are responsibilities or accountabilities of such importance that unacceptable performance will result in a poor performance appraisal. Key performance areas must be formulated thoughtfully because an employee's unacceptable performance can result in disciplinary action. According to Thomas $(1999$, p.41), the following questions assist in identifying key performance areas:

- Is the performance area a major component of the work?

- Does the performance area address individual performance only?

- Are there serious consequences if the employee does not complete his/her work?

- How does underperformance affect the work if the employee fails to perform in one 
of the key performance areas?

It can therefore be concluded that the link between performance management and training and development is crucial. It can almost be seen as parts of an unbroken cycle. If performance management is not implemented correctly, as is the case with the Botswana public service PMS, it will not influence the management of the skills and competence gap. Training priorities will not be determined according to the detrimental needs, but will be based on individual perceptions of what is lacking and what is appropriate. Without the strategic link between performance management and training, neither individual nor departmental training goals nor objectives will be achieved

\section{Analysis}

These critical organisational success factors include: creating a training culture, developing an effective leadership, creating a learning organisation and development of an effective performance management system.

\section{TABLE 1}

\section{MEANS AND STANDARD DEVIATIONS OF SCORES FOR CREATING AN EFFECTIVE TRAINING CULTURE}

\begin{tabular}{|l|l|l|l|l|}
\hline & Create an effective training culture & $\mathbf{N}$ & Mean & Std \\
\hline $\mathbf{1 . 1}$ & $\begin{array}{l}\text { In my organisation excellent service is always } \\
\text { emphasized }\end{array}$ & $\mathbf{8 4}$ & $\mathbf{3 . 5 8 3}$ & $\mathbf{0 . 5 8 5}$ \\
\hline $\mathbf{1 . 2}$ & $\begin{array}{l}\text { In my organisation, employees are encouraged to } \\
\text { develop themselves }\end{array}$ & $\mathbf{8 4}$ & $\mathbf{3 . 6 6 6}$ & $\mathbf{0 . 4 9 8}$ \\
\hline $\mathbf{1 . 3}$ & $\begin{array}{l}\text { My organisation encourages communication } \\
\text { between trainer, training department staff and } \\
\text { employees }\end{array}$ & $\mathbf{8 4}$ & $\mathbf{3 . 7 2 6}$ & $\mathbf{0 . 4 7 4}$ \\
\hline $\mathbf{1 . 4}$ & $\begin{array}{l}\text { My trainer and the rest of the training department } \\
\text { value trainees' opinions on issues relating to } \\
\text { training and development }\end{array}$ & $\mathbf{8 4}$ & $\mathbf{3 . 7 3 8}$ & $\mathbf{0 . 4 4 2}$ \\
\hline $\mathbf{1 . 5}$ & $\begin{array}{l}\text { In my organisation trainees are held accountable } \\
\text { for their training and development }\end{array}$ & $\mathbf{8 4}$ & $\mathbf{3 . 7 2 6}$ & $\mathbf{0 . 4 4 8}$ \\
\hline
\end{tabular}


Analysis of the means scores and standard deviations for the first critical organisational success factors revealed an aggregate mean of 3.7. This suggests a tendency towards disagreement on all the statements. The standard deviation indicated that the spread was relatively narrow, ranging between (0.442) and (0.585), indicating that the respondents were relatively consistent in the way they responded to the items in this section.

\section{TABLE 2}

\section{MEANS AND STANDARD DEVIATIONS OF SCORES FOR DEVELOPING EFFECTIVE LEADERSHIP}

\begin{tabular}{|c|c|c|c|c|}
\hline & Develop effective leadership & $\mathbf{N}$ & Mean & $\begin{array}{l}\text { Std } \\
\text { Deviation }\end{array}$ \\
\hline 2.1 & $\begin{array}{l}\text { In my organisation, trainers are developed into } \\
\text { leaders }\end{array}$ & 84 & 3.523 & 0.502 \\
\hline 2.2 & $\begin{array}{l}\text { Trainers in my organisation encourage trainees to } \\
\text { reach their potential }\end{array}$ & 84 & 3.619 & 0.512 \\
\hline 2.3 & I perceive my trainer to be a leader & 84 & 3.690 & 0.465 \\
\hline 2.4 & $\begin{array}{l}\text { My organisation encourages trainees to solve their } \\
\text { own problems themselves }\end{array}$ & 84 & 3.702 & 0.459 \\
\hline 2.5 & Team work amongst trainees is encouraged & 84 & 3.702 & 0.459 \\
\hline
\end{tabular}

Analysis of the means scores and standard deviations for the second critical organisational success factor revealed an aggregate mean of 3.6. This suggests a tendency towards disagreement on all the statements. The standard deviation indicated that the spread was relatively narrow, ranging between (0.459) and (0.512), indicating that the respondents were relatively consistent in the way they responded to the items in this section. 
TABLE 3 MEANS AND STANDARD DEVIATIONS OF SCORES FOR CREATING A LEARNING ORGANISATION

\begin{tabular}{|l|l|l|l|l|}
\hline & Creating a learning organization & $\mathbf{N}$ & Mean & Std \\
Deviation \\
\hline 3.1 & $\begin{array}{l}\text { My organisation encourages employees to develop } \\
\text { and educate themselves }\end{array}$ & 84 & 3.535 & 0.501 \\
\hline $\begin{array}{l}\text { Employees are encouraged to learn from each } \\
\text { other }\end{array}$ & 84 & 3.535 & 0.590 \\
\hline $\begin{array}{l}\text { Opportunities exist for employees to share } \\
\text { organisational related information with each other }\end{array}$ & 84 & 3.583 & 0.495 \\
\hline 3.4 & $\begin{array}{l}\text { My organisation facilitates learning } \\
\text { My trainer serves as a good role model for me }\end{array}$ & 84 & 3.785 & 0.412 \\
\hline
\end{tabular}

Analysis of the means scores and standard deviations for the third critical organisational success factor revealed an aggregate mean of 3.6. This suggests a tendency towards disagreement on all the statements. The standard deviation indicated that the spread was relatively narrow, ranging between (0.412) and (0.590) indicating that the respondents were relatively consistent in the way they responded to the items in this section.

TABLE 4

MEANS AND STANDARD DEVIATIONS OF SCORES FOR DEVELOPING AN EFFECTIVE PERFORMANCE MANAGEMENT SYSTEM

\begin{tabular}{|l|l|l|l|l|}
\hline $\begin{array}{l}\text { Develop an effective performance management } \\
\text { system }\end{array}$ & $\mathbf{N}$ & Mean & $\begin{array}{l}\text { Std } \\
\text { Deviation }\end{array}$ \\
\hline 4.1 & $\begin{array}{l}\text { My organisation sets suitable performance goals in } \\
\text { line with its vision and mission and broad training } \\
\text { objectives }\end{array}$ & 84 & 3.554 & 0.499 \\
\hline
\end{tabular}




\begin{tabular}{|l|l|l|l|l|}
\hline 4.2 & $\begin{array}{l}\text { In my organisation, performance management is a } \\
\text { collaborative effort between the trainer and trainee }\end{array}$ & 84 & 3.619 & 0.557 \\
\hline 4.3 & $\begin{array}{l}\text { In my organisation employees access the necessary } \\
\text { tools and resources, and provide a supportive } \\
\text { environment for effective performance }\end{array}$ & 84 & 3.666 & 0.474 \\
\hline 4.4 & $\begin{array}{l}\text { My trainer continuously assesses and } \\
\text { communicates trainees' performance progress }\end{array}$ & 84 & 3.678 & 0.469 \\
\hline 4.5 & $\begin{array}{l}\text { My trainer provides on-going coaching, mentoring } \\
\text { and the active pursuit of new knowledge and } \\
\text { learning }\end{array}$ & 84 & 3.702 & 0.459 \\
\hline $\begin{array}{l}\text { My trainer provides trainees with mid-year review } \\
\text { progress reports and a final evaluation feedback }\end{array}$ & 84 & 3.702 & 0.459 \\
\hline
\end{tabular}

Analysis of the means scores and standard deviations for the fourth critical organisational success factor revealed an aggregate mean of 3.7. This suggests a tendency towards disagreement on all the statements. The standard deviation indicated that the spread was relatively narrow, ranging between $(0.459)$ and $(0.557)$, indicating that the respondents were relatively consistent in the way they responded to the items in this section.

It is evident from the above analysis that a training culture, leadership, creation of a learning organisation and the establishment of a performance management system in the Botswana public service are not in place as per the theoretical study and most importantly, according to the theoretical models. The responses obtained from these critical organisational success factors were not positive. It could be concluded that the internal organisational environment strongly discourages effective evaluation of training and development initiatives. The responses overwhelmingly indicate that the majority of respondents do not believe that their ministries and departments have done enough to create a conducive environment for the evaluation of training and development.

\section{Recommendations}

- it is important that the organisation becomes a learning one in which training and development become critical components of efficiency and effectiveness and that a performance management system be incorporated into the training strategy;

- A comprehensive and supportive culture, leadership, creation of a learning organisation and effective performance management system should be established and maintained for the effective evaluation of training and development inititiatives aimed at improving individual, team and organisational performance; and 


\section{$\Lambda$ Macrothink}

- The literature study and the empirical study suggested that the Botswana public service did not give much attention to the continuity of quality production and quality service and increasing productivity levels as an integral part of organisational strategic approach towards competetiveness. This issue needs to be addressed.

\section{Conclusion}

Poor service delivery in the Botswana public service has been a major concern to the government, civil society, and other key players in the economy of the country. Many commentators have urged the government to consider the introduction of stringent public reform programmes to address the productivity decline levels with the view to improve quality service delivery in the public service. Effective training and development evaluation strategies are required to measure change in individual, team and organisational efficiency and effectiveness. This is against the backdrop that two thirds of the public service annual budget goes towards training and development and it is important that training evaluation be conducted to rectify the performance deficiency in the public service sector. It is important for training stakeholders to ensure that an environment conducive for learning to take place through the creation of a training culture, effective leadership, creation of a learning organisation and through the integration of a performance management system into the organisational training and development strategy.

It is evident that almost all the ministries and departments (95\%) had no formal training evaluation in place. Regardless of the number of respondents who indicated that they had attended a course or workshop, it is clear that these training programmes or initiatives were not evaluated. It is also evident that the majority of respondents $(95 \%)$ indicated that there was no training policy in their ministries or departments to provide guidelines on how effective training should be conducted and for its evaluation. It has been discussed under section 4.4.6.2 that training is directly linked to performance management and more specifically to an employee's performance appraisal.

Various authors have emphasised how important performance appraisal is during the training needs analysis. In the absence of a systematic performance appraisal, training needs will be unclear and not aligned to organisational strategic training and development objectives. According to the results, 95 per cent of the respondents indicated that their performance was never appraised while only 5 per cent agreed that their performance was being appraised. Furthermore, 94 per cent of line managers, trainers and supervisors indicated they did not appraise their subordinates' performance. This is a clear indication that indeed the performance management system used by the Botswana public service does not influence training and development decisions, a senario which negatively impacts on training and development relevance and effectiveness. It is also evident that the majority of respondents, 55 per cent, and 35 per cent, rate training as ineffective and very ineffective as a tool to improve organisational performance. Only 10 per cent of respondents believed that training is an effective tool to improve organisational performance. 


\section{Macrothink}

\section{References}

Alu, P. (2004). Training and development. Gaborone: Morula Printers.

Armstrong, M. (2000). Human resources management practice. London: Kogan Page.

Bacal, R. (1999). Performance management. New York: McGraw-Hill.

Department of public service management (2001). Implementation of the performance management

System. Gaborone: Government Printer.

De Vos, A.S., Strydom, H., Fouche, C.B. \& Delport, C. S.L. (2002). Research at grass roots ( $2^{\text {nd }}$ ed.).

Pretoria: Van Schaik.

Dobson, G. (2001). Better practices in performance management. Virginia: Society for Training and Development.

Friedman, G. (2000). Hand book for professional managers. New York: Mc-Graw-Hill Book Company.

Hall, D. J. \& Meh, C. K. (2004). Effective planning in training and development. London. Kogan Page.

Ivancevich, J.M., Gibson, J.L., \& Donnelley (1997). Organisations: Behaviour, structure, processes. $\left(9^{\text {th }}\right.$ ed.). Chicago: Iwirn.

Johnston, I. \& McCleland, B. (1994). The world of training and development. The changing environment. ( $2^{\text {nd }}$ ed.). Vermont: Gower Publishing Company Limited.

Joubert, D. \& Noah, G. (2000). Blueprint for performance management. People Dynamics. $20(2), 18$.

Kreitner, R. \& Kinicki, A. (2001). Organisational behaviour.Boston: Irwin/McGraw-Hill.

McGill, J. (2004). Productivity in the development World. Gaborone: Government Printer.

Organisational Management. (2000). Retrieved February 5. From http://www.omgt/articles/2000/fa 100-4.htm

Price, A. (2004). Human resources management in the business context. ( $2^{\text {nd }}$ ed.). London: Thomson Learning.

Robbins, S.P. (2003). Supervision today. New Jersey: Prentice Hall Inc.

Thomas, J. (1999). Improving employee's performance through the performance appraisal system. Nairobi: Tech \& Pro Associates publishers. 
Werner, A. (2003). Organisational behaviour: A contemporary South African perspective. Pretoria: Van Schaik.

Wright, A. (1994). A Handbook of training management. London: Kogan Page. 